\title{
Engineering Cell Surfaces by Covalent Grafting of Synthetic Polymers to Metabolically-Labeled Glycans
}

\author{
Ruben M. F. Tomás, ${ }^{\dagger}{ }^{\S}$ Benjamin Martyn, ${ }^{\dagger}$ Trisha L. Bailey, ${ }^{\dagger}$ and Matthew I. Gibson*, ${ }^{\dagger}, \ddagger$ \\ ${ }^{\dagger}$ Department of Chemistry, University of Warwick, Gibbet Hill Road, Coventry, CV4 7AL, United Kingdom \\ ${ }^{\ddagger}$ Warwick Medical School, University of Warwick, Gibbet Hill Road, Coventry, CV4 7AL, United Kingdom \\ ${ }^{\S}$ MAS CDT, Senate House, University of Warwick, Coventry CV4 7AL, United Kingdom \\ Supporting Information
}

ABSTRACT: Re-engineering mammalian cell surfaces enables modulation of their phenotype, function, and interactions with external markers and may find application in cell-based therapies. Here we use metabolic glycan labeling to install azido groups onto the cell surface, which can act as anchor points to enable rapid, simple, and robust "click" functionalization by the addition of a polymer bearing orthogonally reactive functionality. Using this strategy, new cell surface functionality was introduced by using telechelic polymers with fluorescence or biotin termini, demonstrating that recruitment of biomacromolecules is possible. This approach may enable the attachment of payloads and modulation of cell function and fate, as well as providing a tool to interface synthetic polymers with biological systems.

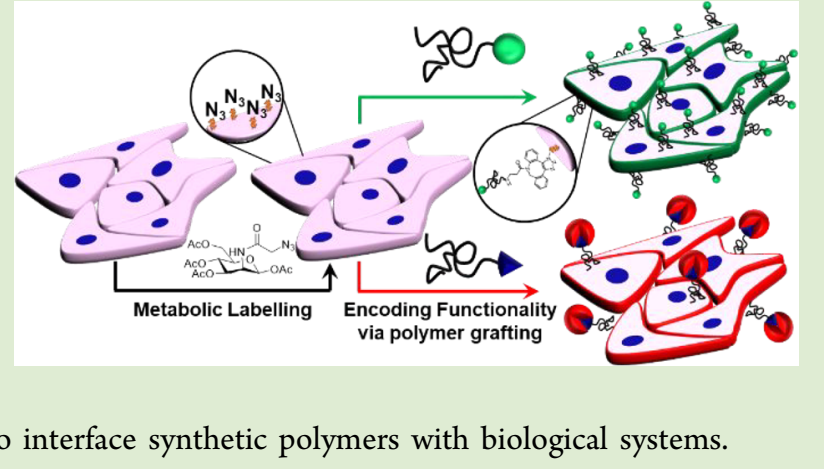

O ell-based therapies are potent tools in modern medicine, from blood transfusions and bone marrow transplants, to rapidly emerging treatments such as stem cell and CAR-T therapy. ${ }^{1-4}$ However, these cells are limited in their native functionality and phenotype. In contrast, synthetic polymerprotein conjugates have shown significant success in improving therapeutic efficacy by increasing stability, circulation half-lives and storage. 5 Such benefits have made PEGylated (poly(ethyene glycol)-grafted) proteins the gold standard in the pharmaceutical industry. ${ }^{6-10}$ Covalent polymer reformulation of cell-based therapies is the next frontier to aid translation, add non-natural functionality, such as imaging agents and/or loading of additional cargo (e.g., therapeutic drugs), and to improve logistics. ${ }^{11-13}$ Therefore, re-engineering of mammalian cell surfaces with synthetic (or natural) polymers is a valuable tool for biomedicine and biotechnology.

Polymer-coated islet cells have been the subject of study to mask cell-surface antigens, minimizing graft rejection in xenogeneic and allogenic transplants, while retaining biological function. ${ }^{14-19}$ Cell PEGylation methods used to achieve this include $N$-hydroxy succinimide and biotin. ${ }^{20-23}$ Similarly, PEGylated erythrocytes can improve blood transfusion compatibility by blocking $\mathrm{AB}$ antigens, while also reducing malaria parasite binding and preventing diseases characterized by impaired blood flow or vaso-occlusion. ${ }^{24-28}$ Despite cellsurface engineering holding great promise, challenges remain in the design of clinical-translatable and effective methods. A successful polymer-remodelling approach should be simple, versatile (i.e., applicable to multiple cell types), bioorthogo$\mathrm{nal}^{29}$ and provide additional functionality, while retaining normal membrane function.
Polyelectrolytes have been investigated for noncovalent electrostatic deposition onto cell membranes for translational applications due to their widespread use as polymer coatings. $^{30,31}$ However, polycations can disrupt the (anionic) cell membrane and rapidly reduce cell viability. Cell viability is reduced even with the incorporation of PEG chains to minimize contact of polyelectrolytes with the lipid bilayer. ${ }^{30-33}$ The susceptibility of nucleated mammalian cells to mechanical and chemical stress also limits the covalent polymer conjugation methods that may be employed. Hawker and coworkers used a "grafting from" approach where ATRP initiators were immobilized onto yeast cells, followed by "grafting from" polymerization. ${ }^{34}$ This approach was found to exert stress on mammalian cells, leading to significant cytotoxicity and hence was not broadly useful for biomedical application. $^{34}$

Genetic tools allow modulation of cell function by introducing or knocking out/silencing genes but, in most cases, they are not adaptable to accept synthetic components. Non-natural amino acids (with bioorthogonal functionality) are challenging to install at specific sites in whole cells. ${ }^{35}$ Therapeutic value is also limited due to tedious and costly transfection procedures along with safety and ethical concerns. ${ }^{36,37}$ As such, exploring novel cytocompatible methods of polymer conjugation to cell surfaces remains a challenging area of biomaterial science.

Received: September 6, 2018

Accepted: October 9, 2018

Published: October 10, 2018 


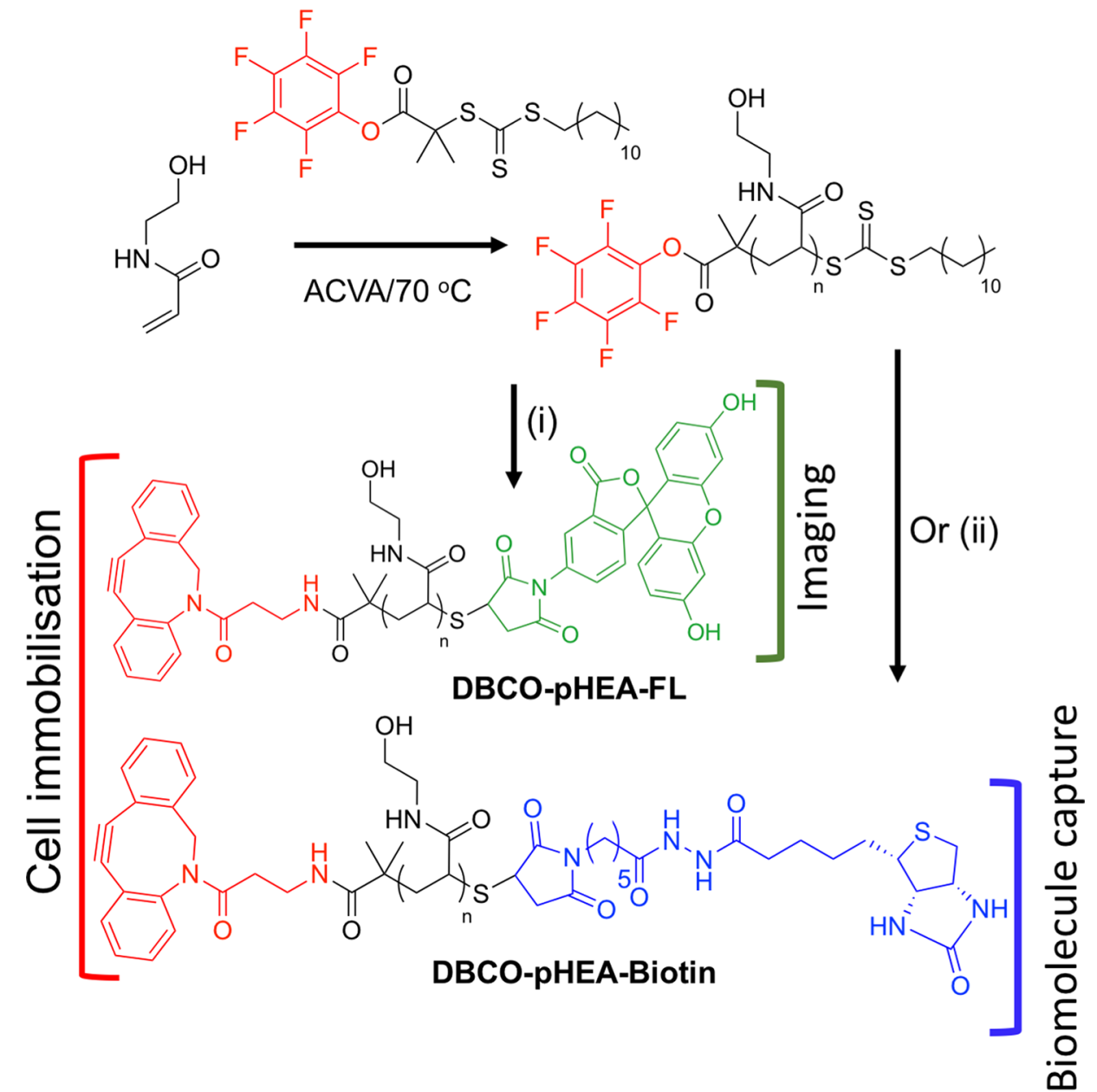

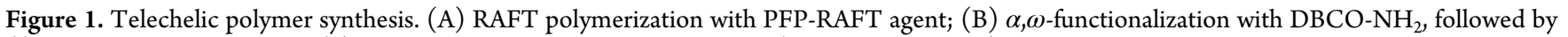
(i) fluorescein maleimide or (ii) biotin maleimide. ACVA = 4,4 Azobis(4-cyanovaleric acid).

Cell-surface glycans play major metabolic, structural, and recognition roles in biology. Glycan metabolic labeling, a technique pioneered by Bertozzi et al., ${ }^{29,38}$ allows azido groups (or other bioorthogonal handles) ${ }^{39}$ to be incorporated into specific cell-surface glycans by "hijacking" oligosaccharide biosynthesis pathways, such as the sialic acid biosynthetic pathway. This tool provides an extremely versatile approach to reprogram cell surfaces using only chemical, rather than genetic, methods. Shi et al. tagged azido-labeled cells with alkynyl-PEG- $\beta$-cyclodextrin and photoswitchable azobenzeneMUC1 aptamer to controllably target epithelial cancer cells (MCF-7) and, thus, promote the formation of T-cell cancer cell assembly. ${ }^{40}$ Furthermore, metabolic labeling has been used to selectively label cancer cells in vivo through the installation of "caged" azido sugars, which are cleaved by canceroverexpressed enzymes. ${ }^{41}$ Liposomal delivery of azido-glycans can also be used for selective cell labeling, targeting overexpressed receptors on cells. ${ }^{42}$ This presents a unique opportunity in biomaterials science to take advantage of controlled polymerization techniques ${ }^{43}$ to enable selective introduction of biorthogonal "click" functionality, ${ }^{44}$ allowing cell surfaces to be re-engineered through purely chemical means.

Here we covalently graft well-defined RAFTed (reversible addition-fragmentation transfer) polymers onto live cells, which have been metabolically labeled using azido-glycans.
Telechelic hydrophilic polymers are subsequently "clicked" onto the modified glycans using strained alkynes, enabling rapid, specific, and biocompatible reprogramming of the cell surface and the introduction of non-native functionality.

Poly(hydroxylethyl acrylamide) (pHEA) was selected for cell-surface remodelling due to its versatility, water solubility, and surface passivation capabilities. ${ }^{45}$ A pentafluorophenyl (PFP) ester functionalized RAFT agent was employed to synthesize telechelic polymers (PFP-pHEA), Figure 1. Polymers were characterized by SEC, ${ }^{1} \mathrm{H},{ }^{13} \mathrm{C}$, and ${ }^{19} \mathrm{~F}$ NMR, and infrared spectroscopy (IR), Table 1 and Supporting Information. Two different chain lengths (DP50 and 100) were prepared with low dispersities, <1.2. Azide-reactive functionality was installed using dibenzocycloctyne-amine $\left(\mathrm{DBCO}-\mathrm{NH}_{2}\right)$ to displace the PFP ester, confirmed by the

Table 1. pHEA Precursor Polymers

$\begin{array}{cccccc}\text { code } & \begin{array}{c}{[\mathrm{M}]:[\mathrm{CTA}]} \\ (-)\end{array} & \begin{array}{c}\text { conv. }^{a} \\ (\%)\end{array} & \begin{array}{c}\left.M_{\mathrm{n}(\text { theo })}\right)^{b} \\ (\mathrm{~g} / \mathrm{mol})\end{array} & \begin{array}{c}M_{\mathrm{n}(\mathrm{SEC})}{ }^{c} \\ (\mathrm{~g} / \mathrm{mol})\end{array} & \bigoplus^{c} \\ \text { PFP-pHEA }_{100} & 100 & 91.3 & 13000 & 15000 & 1.15 \\ \text { PFP-pHEA }_{50} & 50 & 98.2 & 8300 & 9700 & 1.17\end{array}$

${ }^{a}$ Determined by ${ }^{1} \mathrm{H}$ NMR against an internal mesitylene standard. ${ }^{b}$ Determined by the $[\mathrm{M}]:[\mathrm{CTA}]$ ratio and conversion, assuming $100 \%$ CTA efficiency. ${ }^{c}$ Determined by SEC in DMF against PMMA standards. 
removal of PFP peaks in ${ }^{19} \mathrm{~F}$ NMR and IR spectra (Supporting Information). During functionalization, the trithiocarbonate was cleaved revealing a thiol, which was coupled to either fluorescein or biotin maleimide. Conjugation was confirmed via fluorescence spectroscopy after exhaustive dialysis (Supporting Information).

Following polymer synthesis, cell-surface glycans were metabolically labeled. ${ }^{38}$ Adenocarcinomic human alveolar basal epithelial cells (A549 cells), a stable model cell line, were incubated with ManNAz (tetraacylated $\mathrm{N}$-azidoacetylmannosamine), which enters the cell and "hijacks" the sialic acid biosynthetic pathway presenting azido groups on the cell surface. ${ }^{46}$ The presence of cell-surface azides was confirmed by the SPAAC (strain-promoted azide/alkyne click) reagent DBCO-Cy5 (Supporting Information). Confocal microscopy displayed strong localized fluorescence at the cell membrane of ManNAz treated cells, along with cytosolic staining due to nonspecific uptake of the dye (see below). Control cells presented no staining, demonstrating selectivity even in the presence of the myriad of intracellular and extracellular components.

A549 cells were cultured in the presence and absence (negative control) of ManNAz and were subsequently incubated with DBCO-pHEA - -FL at $1-10 \mathrm{mg} / \mathrm{mL}$ for $1 \mathrm{~h}$ (initial screening showed this was sufficient for labeling), Figure 2. The highly specific nature, and rapid kinetics, of azide-alkyne reactions allowed the conjugation process to be undertaken in complete cell media, removing risks of starvation and thus exertion of unnecessary cellular stress. Membraneassociated (green) fluorescence was observed in cells treated with ManNAz at all polymer concentrations used, in a dosedependent manner. The absence of polymer-associated fluorescence in control cells (no ManNAz) confirmed that "click" conjugation occurred, rather than nonspecific mechanisms (such as membrane insertion) ${ }^{47}$ or cellular uptake (endocytosis).

Cell viability was assessed after $24 \mathrm{~h}$ of polymer exposure by the resazurin reduction assay (Supporting Information). At all concentrations there was no reduction in viability and the cell morphology was also unaffected by polymer incubation.

Compared to small molecule probes, which require DMSO solubilization, $\mathrm{p}(\mathrm{HEA})-\mathrm{DBCO}$ polymers offered several advantages due to their high water solubility. DMSO promotes cell uptake, hence, small molecule probes lead to off-target cytosolic labeling, whereas the low cell permeability of watersoluble polymers ensures selective extracellular interactions. The approach presented here provides benefits compared to the "grafting from" approach used by Hawker et al., which required fine-tuning to avoid damage to cells, or the use of robust yeast cells. ${ }^{34}$ Confocal images of labeled cells (Figure 2) showed that DP50 polymers gave increased membrane labeling at all concentrations compared to DP100, potentially due to a combination of lower molar concentrations and increased steric hindrance. Hence, the macromolecular engineering of the grafted layer was crucial to the success of this methodology.

Having demonstrated successful cell labeling, the robustness of the polymer coating was evaluated, which is crucial due to the potential recycling of glycan anchors. ${ }^{48}$ Established methods of coating cells, such as lipid anchors, ${ }^{47}$ suffer from lack of robustness due to membrane recycling and polymer dissociation due to weak hydrophobic interactions. ${ }^{11}$ Polymerlabeled cells were imaged over $24 \mathrm{~h}$ by monitoring fluorescein (green) fluorescence, Figure 3. Image cytometry showed a
(A)

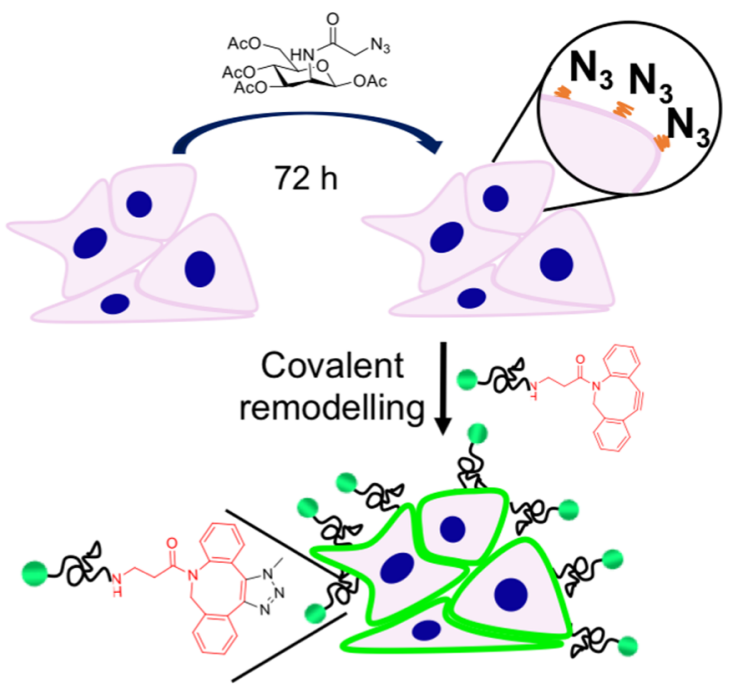

(B)

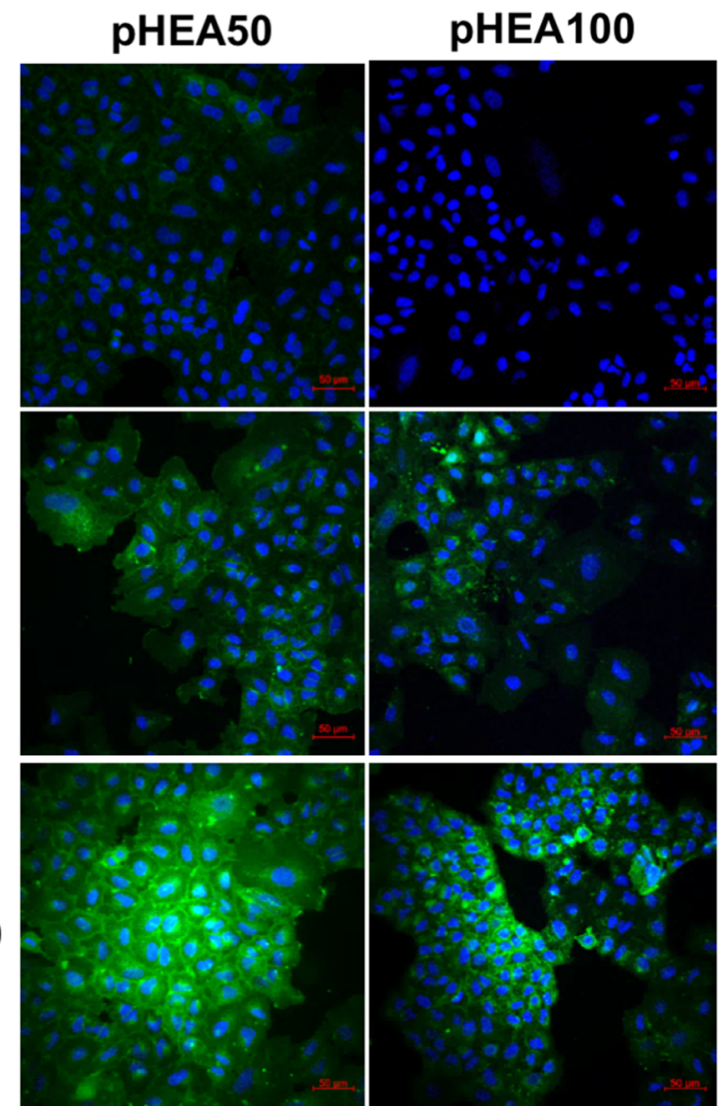

Figure 2. Covalent grafting of polymers to azido-labeled cells. (A) Incubation of A549 cells with ManNAz, followed by SPAAC at the cell surface; (B) Confocal images of ManNAz treated cells exposed to indicated concentrations of DBCO-pHEA ${ }_{n}$-FL (green) for $1 \mathrm{~h}(n=$ 3); Blue: DAPI (nuclear) stain. Scale bar $=50 \mu \mathrm{m}$.

relatively even distribution of labeling and degrafting across the population (Supporting Information). Total average fluorescence suggested that DP50 polymers retained over $2 \times$ greater surface coverage compared to DP100 polymers, even $24 \mathrm{~h}$ postconjugation. However, initial degrafting of $\mathrm{pHEA}_{50}$ occurred within $8 \mathrm{~h}$ whereas loss of pHEA $_{100}$ occurred later, between 8 and $16 \mathrm{~h}$ following conjugation. Thus, this may present opportunities for temporal control over conjugation using polymer length. No evidence was found of increased 


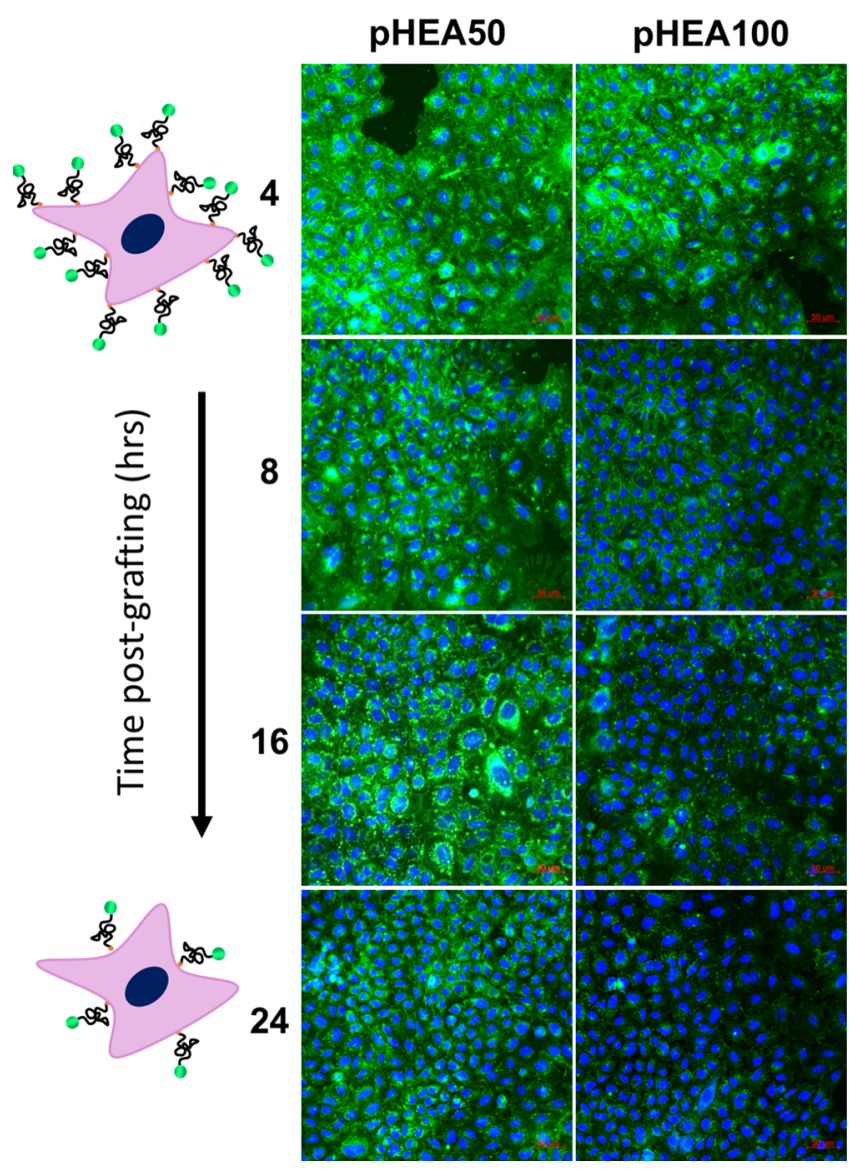

Figure 3. Grafting lifetime of glycan-immobilized polymers. Timelapse confocal images over $24 \mathrm{~h}$ are shown $(n=3)$; Blue: DAPI (nuclear) stain; Green: DBCO-pHEA ${ }_{n}$-FL polymer $(10 \mathrm{mg} / \mathrm{mL})$. Scale bar $=50 \mu \mathrm{m}$.

intracellular green fluorescence, suggesting that the fate of cell surface polymers was degrafting rather than uptake and processing.

Following the above success, we wanted to demonstrate that additional functionality can be brought to the cell surface using these polymers while retaining availability of the nongrafted chain end (and not sterically limited by, for example, the glycocalyx). This approach enables encoding of additional information to the cell surface without using genetic engineering. Biotin-maleimide was introduced to the thiol chain end of polymers (Figure 1). Cells treated with azido sugars were subsequently functionalized with the biotinylated polymers, using the optimized procedures described above. Cy3-labeled (red) streptavidin was introduced either immediately, or $24 \mathrm{~h}$ after, incubation with polymers. Confocal images of pHEA-biotinylated cells after incubation with streptavidin demonstrated clear membrane associated red fluorescence consistent with recruitment of streptavidin to the cell surface, Figure 4. Due to the increased loading of the DP50 polymers, there was approximately double (values in Supporting Information) the recruitment extent of streptavidin compared to DP100. This model system demonstrates the versatility of this method to re-engineer cells with non-native functionality using accessible and versatile tools.

In summary, we have covalently grafted synthetic polymers onto the surface of living cells. The tethering point is introduced to A549 cells by metabolic labeling of cell surface
(A)

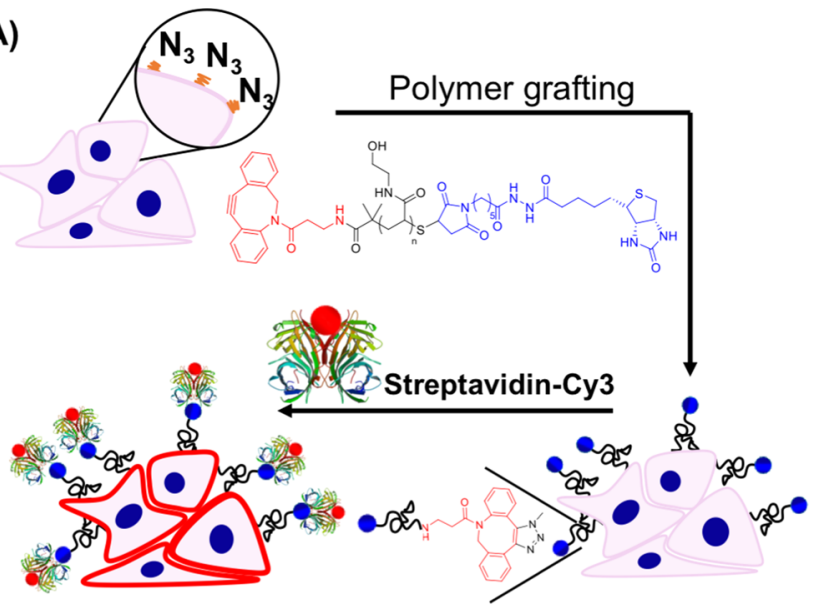

(B)
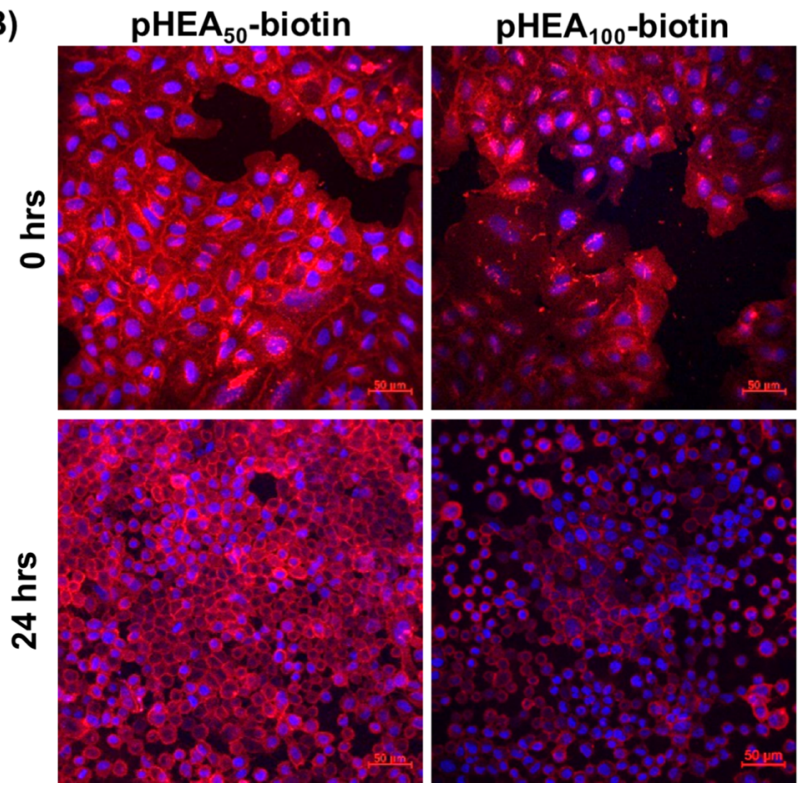

Figure 4. Recruitment of streptavidin to polymer-remodelled cell surfaces. (A) Immobilization of DBCO-pHEA ${ }_{n}$-biotin to azidofunctionalized A549 cells, followed by recruitment of StrepavidinCy3 (red); (B) Time lapse confocal images of cells after streptavidin recruitment $(n=3)$; Blue: DAPI (nuclear) stain. Scale bar $=50 \mu \mathrm{m}$.

glycans by acetylated $N$-azidoacetylmannosamine (ManNAz). This azide was then used to anchor telechelic polymers via strain-promoted azide/alkyne "click" reaction. The optimized polymers remain on the cell surface for over $24 \mathrm{~h}$, which is longer than reported for lipid-remodelling methods. Furthermore, the extent and durability of the grafting was found to be linked to the molecular weight of the polymer chain used. Additional functionality was introduced through biotinterminated polymers, which were immobilized onto the cell surface and subsequently used to recruit fluorophore labeled streptavidin to the surface. Hence, demonstrating applicability in biomedical engineering and offering several advantages over genetic encoding methods. In this study, we have devised a versatile yet simple approach to remodel cell surfaces that will find application in cell-based therapies and for fundamental studies on cell surface interactions. 


\section{ASSOCIATED CONTENT}

\section{S Supporting Information}

The Supporting Information is available free of charge on the ACS Publications website at DOI: 10.1021/acsmacrolett.8b00675.

Experimental procedures and characterization data, plus additional binding experiments (PDF).

\section{AUTHOR INFORMATION}

\section{Corresponding Author}

*E-mail: m.i.gibson@warwick.ac.uk.

\section{ORCID $\odot$}

Matthew I. Gibson: 0000-0002-8297-1278

\section{Author Contributions}

The manuscript was written through contributions of all authors. All authors have given approval to the final version. The research data supporting this publication can be accessed at http://wrap.warwick.ac.uk.

\section{Notes}

The authors declare no competing financial interest.

\section{ACKNOWLEDGMENTS}

M.I.G. holds an ERC Starter Grant (CRYOMAT 638661). R.T. thanks EPSRC for a Ph.D. studentship through the EPSRC Centre for Doctoral Training in Molecular Analytical Science, (EP/L015307/1RT), and to B.M (EP/M506679/1). UoW Advanced BioImaging RTP BBSRC ALERT14 Award $\mathrm{BB} / \mathrm{M} 01228 \mathrm{X} / 1$ and polymer characterization RTP are thanked.

\section{REFERENCES}

(1) Park, J. H.; Rivière, I.; Gonen, M.; Wang, X.; Sénéchal, B.; Curran, K. J.; Sauter, C.; Wang, Y.; Santomasso, B.; Mead, E.; Roshal, M.; Maslak, P.; Davila, M.; Brentjens, R. J.; Sadelain, M. Long-Term Follow-up of CD19 CAR Therapy in Acute Lymphoblastic Leukemia. N. Engl. J. Med. 2018, 378 (5), 449-459.

(2) Smith, A. J.; Oertle, J.; Warren, D.; Prato, D. Chimeric Antigen Receptor (CAR) T Cell Therapy for Malignant Cancers: Summary and Perspective. J. Cell. Immunother. 2016, 2 (2), 59-68.

(3) Fraietta, J. A.; Lacey, S. F.; Orlando, E. J.; Pruteanu-Malinici, I.; Gohil, M.; Lundh, S.; Boesteanu, A. C.; Wang, Y.; O'connor, R. S.; Hwang, W. T.; Pequignot, E.; Ambrose, D. E.; Zhang, C.; Wilcox, N.; Bedoya, F.; Dorfmeier, C.; Chen, F.; Tian, L.; Parakandi, H.; Gupta, M.; Young, R. M.; Johnson, F. B.; Kulikovskaya, I.; Liu, L.; Xu, J.; Kassim, S. H.; Davis, M. M.; Levine, B. L.; Frey, N. V.; Siegel, D. L.; Huang, A. C.; Wherry, E. J.; Bitter, H.; Brogdon, J. L.; Porter, D. L.; June, C. H.; Melenhorst, J. J. Determinants of Response and Resistance to CD19 Chimeric Antigen Receptor (CAR) T Cell Therapy of Chronic Lymphocytic Leukemia. Nat. Med. 2018, 24 (5), 563-571.

(4) Maude, S. L.; Laetsch, T. W.; Buechner, J.; Rives, S.; Boyer, M.; Bittencourt, H.; Bader, P.; Verneris, M. R.; Stefanski, H. E.; Myers, G. D.; Qayed, M.; De Moerloose, B.; Hiramatsu, H.; Schlis, K.; Davis, K. L.; Martin, P. L.; Nemecek, E. R.; Yanik, G. A.; Peters, C.; Baruchel, A.; Boissel, N.; Mechinaud, F.; Balduzzi, A.; Krueger, J.; June, C. H.; Levine, B. L.; Wood, P.; Taran, T.; Leung, M.; Mueller, K. T.; Zhang, Y.; Sen, K.; Lebwohl, D.; Pulsipher, M. A.; Grupp, S. A. Tisagenlecleucel in Children and Young Adults with B-Cell Lymphoblastic Leukemia. N. Engl. J. Med. 2018, 378 (5), 439-448.

(5) Mancini, R. J.; Lee, J.; Maynard, H. D. Trehalose Glycopolymers for Stabilization of Protein Conjugates to Environmental Stressors. J. Am. Chem. Soc. 2012, 134 (20), 8474-8479.
(6) Borchmann, D. E.; Carberry, T. P.; Weck, M. Bio"-Macromolecules: Polymer-Protein Conjugates as Emerging Scaffolds for Therapeutics. Macromol. Rapid Commun. 2014, 35 (1), 27-43.

(7) Larson, N.; Ghandehari, H. Polymeric Conjugates for Drug Delivery. Chem. Mater. 2012, 24, 840-853.

(8) Qi, Y.; Chilkoti, A. Protein-Polymer Conjugation-Moving beyond PEGylation. Curr. Opin. Chem. Biol. 2015, 28, 181-193.

(9) Jones, M. W.; Strickland, R. A.; Schumacher, F. F.; Caddick, S.; Baker, J. R.; Gibson, M. I.; Haddleton, D. M. Polymeric Dibromomaleimides as Extremely Efficient Disulfide Bridging Bioconjugation and Pegylation Agents. J. Am. Chem. Soc. 2012, 134 (3), 1847-1852.

(10) Pelegri-Oday, E. M.; Lin, E. W.; Maynard, H. D. Therapeutic Protein-Polymer Conjugates: Advancing beyond Pegylation. J. Am. Chem. Soc. 2014, 136 (41), 14323-14332.

(11) Matthias, T.; Irvine, D. Enhancing Cell Therapies from the Outside In: Cell Surface Engineering Using Synthetic Nanomaterials. Nano Today 2011, 6 (3), 309-325.

(12) Graham, B.; Bailey, T. L.; Healey, J. R. J.; Marcellini, M.; Deville, S.; Gibson, M. I. Polyproline Is a Minimal Antifreeze Protein Mimetic and Enhances the Cryopreservation of Cell Monolayers. Angew. Chem., Int. Ed. 2017, 56, 15941-15944.

(13) Mitchell, D. E.; Lovett, J. R.; Armes, S. P.; Gibson, M. I. Combining Biomimetic Block Copolymer Worms with an IceInhibiting Polymer for the Solvent-Free Cryopreservation of Red Blood Cells. Angew. Chem., Int. Ed. 2016, 55 (8), 2801-2804.

(14) Dong, H.; Fahmy, T. M.; Metcalfe, S. M.; Morton, S. L.; Dong, X.; Inverardi, L.; Adams, D. B.; Gao, W.; Wang, H. Immuno-Isolation of Pancreatic Islet Allografts Using Pegylated Nanotherapy Leads to Long-Term Normoglycemia in Full MHC Mismatch Recipient Mice. PLoS One 2012, 7 (12), e50265.

(15) Krol, S.; Del Guerra, S.; Grupillo, M.; Diaspro, A.; Gliozzi, A.; Marchetti, P. Multilayer Nanoencapsulation. New Approach for Immune Protection of Human Pancreatic Islets. Nano Lett. 2006, 6 (9), 1933-1939.

(16) Gattás-Asfura, K. M.; Stabler, C. L. Bioorthogonal Layer-byLayer Encapsulation of Pancreatic Islets via Hyperbranched Polymers. ACS Appl. Mater. Interfaces 2013, 5 (20), 9964-9974.

(17) Blasi, P.; Luca, G.; Mancuso, F.; Schoubben, A.; Calvitti, M.; Giovagnoli, S.; Basta, G.; Becchetti, E.; Ricci, M.; Calafiore, R. Conformal Polymer Coatings for Pancreatic Islets Transplantation. Int. J. Pharm. 2013, 440 (2), 141-147.

(18) Teramura, Y.; Kaneda, Y.; Iwata, H. Islet-Encapsulation in Ultra-Thin Layer-by-Layer Membranes of Poly(Vinyl Alcohol) Anchored to Poly(Ethylene Glycol)-Lipids in the Cell Membrane. Biomaterials 2007, 28 (32), 4818-4825.

(19) Cabric, S.; Sanchez, J.; Lundgren, T.; Foss, A.; Felldin, M.; Källen, R.; Salmela, K.; Tibell, A.; Tufveson, G.; Larsson, R.; Korsgren, O.; Nilsson, B. Islet Surface Heparinization Prevents the Instant Blood-Mediated Inflammatory Reaction in Islet Transplantation. Diabetes 2007, 56 (8), 2008-2015.

(20) Teramura, Y.; Kaneda, Y.; Totani, T.; Iwata, H. Behavior of Synthetic Polymers Immobilized on a Cell Membrane. Biomaterials 2008, 29 (10), 1345-1355.

(21) Teramura, Y.; Iwata, H. Islets Surface Modification Prevents Blood-Mediated Inflammatory Responses. Bioconjugate Chem. 2008, 19 (7), 1389-1395.

(22) Rengifo, H. R.; Giraldo, J. A.; Labrada, I.; Stabler, C. L. LongTerm Survival of Allograft Murine Islets Coated via Covalently Stabilized Polymers. Adv. Healthcare Mater. 2014, 3 (7), 1061-1070.

(23) Gołąb, K.; Kizilel, S.; Bal, T.; Hara, M.; Zielinski, M.; Marektrzonkowska, N.; Millis, J. M.; Trzonkowski, P. Improved Coating of Pancreatic Islets with Regulatory $\mathrm{T}$ Cells (Tregs) to Create Local Immunosuppression by Using Biotin- Polyethylene Glycol-Succinimidyl Valeric Acid Ester Molecule. Transplant. Proc. 2014, 46 (6), 1967-1971.

(24) Garratty, G. Progress in Modulating the RBC Membrane to Produce Transfusable Universal/Stealth Donor RBCs. Transfusion Medicine Reviews 2004, 18, 245-256. 
(25) Garratty, G. Modulating the Red Cell Membrane to Produce Universal/Stealth Donor Red Cells Suitable for Transfusion. Vox Sang. 2007, 0, 87-95.

(26) Bradley, A. J.; Murad, K. L.; Regan, K. L.; Scott, M. D. Biophysical Consequences of Linker Chemistry and Polymer Size on Stealth Erythrocytes: Size Does Matter. Biochim. Biophys. Acta, Biomembr. 2002, 1561 (2), 147-158.

(27) Blackall, D. P.; Armstrong, J. K.; Meiselman, H. J.; Fisher, T. C. A-Specific Antibodies and Are Impervious to Invasion by the Plasmodium Falciparum Malaria Parasite Polyethylene Glycol Coated Red Blood Cells Fail to Bind Glycophorin A - Specific Antibodies and Are Impervious to Invasion by the Plasmodium Falciparum Ma. Blood 2001, 97 (2), 551-556.

(28) Stott, M. D.; Murad, K. L.; Kooumpouras, F.; Talbot, M.; Eaton, J. W.; Scott, M. D.; Koumpouras, F. Chemical Camouflage of Antigenic Determinants: Stealth Erythrocytes. Proc. Natl. Acad. Sci. U. S. A. 1997, 94 (14), 7566-7571.

(29) Prescher, J. A.; Bertozzi, C. R. Chemistry in Living Systems. Nat. Chem. Biol. 2005, 1 (1), 13-21.

(30) Lee, D. Y.; Park, S. J.; Lee, S.; Nam, J. H.; Byun, Y. Highly Poly(Ethylene) Glycolylated Islets Improve Long-Term Islet Allograft Survival without Immunosuppressive Medication. Tissue Eng. 2007, 13 (8), 2133-2141.

(31) Wilson, J. T.; Cui, W.; Kozlovskaya, V.; Kharlampieva, E.; Pan, D.; Qu, Z.; Krishnamurthy, V. R.; Mets, J.; Kumar, V.; Wen, J.; Song, Y.; Tsukruk, V. V.; Chaikof, E. L. Cell Surface Engineering with Polyelectrolyte Multilayer Thin Films. J. Am. Chem. Soc. 2011, 133 (18), 7054-7064.

(32) Wilson, J. T.; Cui, W.; Chaikof, E. L. Supporting Information Layer-by-Layer Assembly of a Conformal Nano-Thin PEO Coating for Intraportal Islet Transplantation. Nano Lett. 2008, 8 (7), 19401948.

(33) Zhang, P.; Bookstaver, M. L.; Jewell, C. M. Engineering Cell Surfaces with Polyelectrolyte Materials for Translational Applications. Polymers (Basel, Switz.) 2017, 9 (2), 1-21.

(34) Niu, J.; Lunn, D. J.; Pusuluri, A.; Yoo, J. I.; O’Malley, M. A.; Mitragotri, S.; Soh, H. T.; Hawker, C. J. Engineering Live Cell Surfaces with Functional Polymers via Cytocompatible Controlled Radical Polymerization. Nat. Chem. 2017, 9 (6), 537-545.

(35) Chin, J. W. Expanding and Reprogramming the Genetic Code. Nature 2017, 550, 53-60.

(36) Naldini, L. Gene Therapy Returns to Centre Stage. Nature 2015, 526, 351-360.

(37) Verma, I. M.; Weitzman, M. D. GENE THERAPY: TwentyFirst Century Medicine. Annu. Rev. Biochem. 2005, 74 (1), 711-738.

(38) Saxon, E.; Bertozzi, C. R. Cell Surface Engineering by a Modified Staudinger Reaction. Science 2000, 287 (5460), 2007-2010.

(39) Stairs, S.; Neves, A. A.; Stöckmann, H.; Wainman, Y. A.; Ireland-Zecchini, H.; Brindle, K. M.; Leeper, F. J. Metabolic Glycan Imaging by Isonitrile-Tetrazine Click Chemistry. ChemBioChem 2013, 14 (9), 1063-1067.

(40) Shi, P.; Ju, E.; Yan, Z.; Gao, N.; Wang, J.; Hou, J.; Zhang, Y.; Ren, J.; Qu, X. Spatiotemporal Control of Cell-Cell Reversible Interactions Using Molecular Engineering. Nat. Commun. 2016, 7, 19.

(41) Wang, H.; Wang, R.; Cai, K.; He, H.; Liu, Y.; Yen, J.; Xu, M.; Yiwen Sun, X. Z. Selective in Vivo Metabolic Cell-Labeling-Mediated Cancer Targeting. Nat. Chem. Biol. 2017, 13, 415-424.

(42) Xie, R.; Hong, S.; Feng, L.; Rong, J.; Chen, X. Cell-Selective Metabolic Glycan Labeling Based on Ligand-Targeted Liposomes. J. Am. Chem. Soc. 2012, 134 (24), 9914-9917.

(43) Boyer, C.; Bulmus, V.; Davis, T. P.; Ladmiral, V.; Liu, J.; Perrier, S. Bioapplications of RAFT Polymerization. Chem. Rev. 2009, 109 (11), 5402-5436.

(44) McKay, C. S.; Finn, M. G. Click Chemistry in Complex Mixtures: Bioorthogonal Bioconjugation. Chem. Biol. 2014, 21, 10751101.

(45) Richards, S.-J.; Gibson, M. I. Optimization of the Polymer Coating for Glycosylated Gold Nanoparticle Biosensors to Ensure
Stability and Rapid Optical Readouts. ACS Macro Lett. 2014, 3 (10), 1004-1008.

(46) Laughlin, S. T.; Bertozzi, C. R. Metabolic Labeling of Glycans with Azido Sugars and Subsequent Glycan-Profiling and Visualization via Staudinger Ligation. Nat. Protoc. 2007, 2 (11), 2930-2944.

(47) Huang, M. L.; Smith, R. A. A.; Trieger, G. W.; Godula, K. Glycocalyx Remodeling with Proteoglycan Mimetics Promotes Neural Specification in Embryonic Stem Cells. J. Am. Chem. Soc. 2014, 136 (30), 10565-10568.

(48) Nischan, N.; Kohler, J. J. Advances in Cell Surface Glycoengineering Reveal Biological Function. Glycobiology 2016, 26 (8), $1-8$. 